\title{
A Serials Acquisitions Cost Study
}

\section{Presenting a Case for Standard Serials Acquisitions Data Elements}

\author{
David C. Fowler and Janet Arcand
}

This paper is based on time and cost studies conducted at Iowa State University (ISU) between 1986/87 and 2000/2001. Serials acquisitions functions were evaluated and examined with a view toward using the results as a management tool. Previous cost center papers by the authors and others focused only on monograph acquisition functions. Analysis of the data collected at ISU suggests that libraries that have developed standards for serials acquisitions processing could reap significant benefits through the use of consistent sets of information for management decisions, including, but not limited to, reassigning staff time to new and evolving tasks.

$\mathrm{O}$ rganizations of all types all around the world and through history have sought to measure their effectiveness in relation to their particular stated mission. One way that these organizations accomplished this was by examining the variables generated by the actions within or outputs of their operations. Two of the most important variables that can be measured are staff time (the amount of chronological units expended by employees in accomplishing their tasks in service of the organization's goals) and cost (the amount of financial units expended in accomplishing these particular operations).

The broad goal of this endeavor is to increase the organization's effectiveness by examining and measuring which expendable resources (such as personnel time and money) are being allocated and how they are being used. By doing this, managers and administrators are better able to comprehend how their organization functions, the extent to which it meets its stated (and unstated) goals, and how that performance can be improved.

Research in the arena of time and cost studies continues to be a relevant is the cowler (dfowler@iastate.edu) for Acquisitions and Janet Arcand (jarcand@iastate.edu) is the Head of the Acquisitions Department at lowa State University Library, Ames.

Acknowledgements: The authors wish to thank Dilys E. Morris, Lori Osmus, and Kris Gerhard for their assistance and encouragement in the analysis and writing of this article and of our previous paper. Dilys Morris also was the driving force behind the original cost study project and was instrumental in compiling and archiving the cost study data. tool for administrators and is useful for defining existing trends and predicting future directions for which the organization needs to prepare. This type of research can be especially valuable for libraries in the current environment, where administrators have an expectation that libraries will be able to prove the value and efficiency of the services that they provide. In 2003, Calhoun ambitiously stated that, "To achieve the results they need, technical services departments need breakthrough, double-digit improvements in cost, time, and effectiveness."

Between 1986/87 and 2000/2001, the Iowa State University (ISU) library created and implemented an exhaustive time and cost study that examined these 
factors within that library's technical services division. The study was begun in April 1987 and was suspended at ISU after 2001. Previous papers based upon time and cost study data gathered at ISU have proved of interest to the general library community in providing insight into operational structure and planning. This paper largely follows the pattern established by previously published papers that were based on the ISU time and cost study data. ${ }^{2}$

At ISU the originators of the cost study assumed that automation would enable the library to reduce staff costs and time, and improve services. This, however, turned out to be only partially true in the case of serials acquisitions. Because of automation, the library found it was able to do more work with the same amount of staffing - it was able to take on new assignments (such as government document processing) and enhance the value of its products (improving the accuracy of reports and providing order and receipt information to the public). However, the amount of time expended overall was not reduced, and costs consistently rose throughout the period of the cost study. The need to maintain long-term commitments to serials subscriptions appeared to limit the library's ability to reduce staffing and costs. Based on analysis at ISU, the most significant cause for the inability to make reductions appeared to be a lack of uniform or standard acquisitions processing data elements. The authors believe that time and costs could be improved if such standard elements were created and used.

No such officially designated standards for data elements exist in the library profession. For the purpose of this paper, these envisioned acquisitions processing standards will be defined as acquisitions data elements pertaining to the library's individual acquisitions arrangements and its local collection management needs. They are defined within the library's integrated library system (ILS), either in the acquisitions module or in related modules.

\section{ISU Time and Cost Studies}

Because of the wealth of raw data available from years of statistical reporting, a number of papers have been published based on time and cost analysis of various functions of library technical service operations at ISU. These papers focused upon aspects of cataloging and explored the effect of automation on costs and of the evolving national database of bibliographic records; they also identified work processes of high cost as fruitful areas to analyze with the goal of continuing cost reduction. ${ }^{3}$ Two studies focused upon early data on the high costs of acquiring monographs. Rebarcak and Morris described their analysis of the then most recent complete year of data, 1994/95, and analyzed the productive and nonproductive elements of the monographs acquisitions work processes. ${ }^{4}$ Morris, Rebarcak, and
Rowley analyzed several years of then-recent data, from 1990/91 through 1994/95, to obtain a clearer view of the relevant time and cost centers over the passage of time, and drew conclusions that initial automation efforts had only a limited impact upon acquisition costs, due to limitations in the scope of the changes that were implemented. ${ }^{5}$ Fowler and Arcand continued the monographs acquisitions analysis covering 1995/96 through 2000/2001. ${ }^{6}$

\section{Literature Review}

Aside from previous papers on the ISU time and cost studies, the authors found little in the library literature that addressed the area of cost analysis of library technical services operations, and very little that specifically addressed the impact of standard data elements in a serials acquisitions environment. Five works of scholarship, however, do seem to have relevancy.

"The Future of Standards" by Paul indicated that acquisitions processing standards exist or are in the process of being created or refined for material formats and for buyer-seller communications, and are of interest to the general library community. ${ }^{7}$ Because of the large number of stakeholders involved, the process of defining and adopting these standards has led to a proliferation of competing models, which may only exacerbate the problem. Attempts to create consensus have been subject to frequent breakdowns. This also has been illustrated in the area of national standards versus international standards, as well as with processing standards developed by the library community, which have proved to be unacceptable to the publishing community. Paul ultimately envisioned a future in which common processing standards will speed up the processing of communications.

The second article, "Standards! Standards! Standards! Experiences with Standards at the University of Georgia Libraries," was written by Somers. ${ }^{8}$ Somers detailed the experience of the University of Georgia (UG) libraries, where MARC bibliographic standards were deliberately ignored during the design of their local acquisitions and cataloging system, which negatively affected the library by making participation in any cooperative cataloging ventures, or inputting their own data in the national database, difficult or impossible. The UG library was later forced to go to enormous expense, time, and effort to make their cataloging information MARC-compatible. Later automation efforts were able to use this experience in determining how to incorporate standards as the basis for decision making. The pre-implementation planning to do this was considerable, but the end result was well worth it, resulting in an efficiently running system. The UG libraries did create their own in-house acquisitions data fields (which, 
although not identified as such in the paper, appear to be prototypical acquisitions data element standards)—fields that they had to ensure would continue to exist after they became MARC compatible.

Farrell and Truitt wrote the third paper of note, "The Case for Acquisitions Standards in the Integrated Library System." This described the historical setting behind the current need for standardization of what the authors referred to as "acquisitions metadata," and, further, made the case for defining a conceptual framework for acquisitions standards, activity segments (which bear some similarity to ISU's cost centers), data elements, and generic interfaces. These can be defined on a national level, since the problem and need is more than just local. The paper also discussed current standards for communications or cataloging needs. The authors stated that, "We need to recognize that administrative metadata such as that created during the acquisitions process is as critical to managing our collections, as bibliographic metadata is critical to providing access to them." ${ }^{" 10}$ In other words, a uniform application of this administrative metadata, which the authors of this paper would characterize as standardized acquisitions data elements, if used properly and uniformly across libraries, could engender an evolution or even a revolution in acquisitions operations on a level that MARC records did for cataloging operations.

Farrell and Truitt also noted that, "Libraries routinely enrich (or have the need to enrich) acquisitions metadata to support local processes. We invest untold thousands of hours of staff time carrying out this enrichment."11 Finally, they stated that:

Increasingly, though, library managers at various levels are turning to the integrated system, perceiving it to be a rich source of data that can aid in the management of library budgets, collections, vendors, etc. Unfortunately, because neither the systems designers nor we viewed either data or system functionality with an eye to this new use, the results of our attempts to manage through the ILS have been at best mixed. Agreed-upon acquisitions standards would tend to enforce more disciplined thinking about the uses to which we put both our systems and our administrative metadata and would mark a major first step toward designing systems that are "management-friendly." 12

The fourth paper is "Starting with an Empty Map: Benchmarking Time and Costs for Serials Operations" by Slight-Gibney and Grenci. ${ }^{13}$ This was a brief report at a workshop about a University of Oregon technical services time and cost study that focused on serials operations. The subject matter was relevant, but due to the workshop setting, the paper focused on methodology and contained only a cursory examination of the resulting data. The authors concluded that benchmarking studies were valuable and needed to be done in other institutions.

The fifth paper, and the most recent of note, was "The Nonsubscription Side of Periodicals: Changes in Library Operations and Costs between Print and Electronic Formats" by Schonfield et al. ${ }^{14}$ In this useful and ambitious report, the authors test the assumption that cost reductions and staffing savings can be made as libraries transition from print to online journals. Eleven libraries of varying sizes participated in the study, which identified the nonsubscription costs for ordering and maintaining periodicals: these included space, equipment, and binding as well as staffing. The staffing time and costs, which covered the serial-related activities of the acquisitions staff, among others, were compiled through the use of activity logs and staff salary data. The focus for the analysis was the comparison of costs for electronic and print journals, and the authors devised a formula to project the libraries' future costs for acquiring and maintaining their journals. Although the report concluded that all libraries should be able to reduce their costs by transitioning to online journals, they also assessed that some of the reduction might pose new problems in terms of staffing reassignments:

Because of the varying skill sets of individuals and the difficulty of reallocating relatively small amounts of employees' time expenditures, it would probably be impossible to reallocate all the staff time expenditures in perfectly efficient ways. . . . Realizing the full potential cost decreases would pose a significant management challenge. ${ }^{15}$

An ongoing resource for the discussion of serials acquisitions standards is the Association for Library Collections \& Technical Services (ALCTS) Automated Acquisitions/ In-Process Control Systems Discussion Group, which meets twice yearly at American Library Association Annual Conference and Midwinter Meetings. ${ }^{16}$ Members of the discussion group also maintain a discourse throughout the year on the subject of acquisitions standards by hosting an electronic discussion group, AUTOACQ-L. ${ }^{17}$ A review of relevant postings to the group reveals that some members are attempting to define separate data elements that are important in terms of populating acquisitions records, their usefulness in communication, and their flexibility for manipulation. Some members have indicated that a structural framework should be created first, defining the broad functional phases of the acquisitions process, such as selection, pre-order, order, order maintenance, receipt, and payment, as well as reporting requirements.

Many electronic discussion postings in this area have been about defining a conceptual framework prior to get- 
ting into specific elements and about discouraging rush jobs that only suit current needs or needs of a narrow audience; these postings have encouraged users to ensure that the end result is a viable product for the future and for farranging needs. Such sentiments would tend to support the authors' contention that such standardized acquisitions data elements are not yet in existence, but that acquisitions professionals are beginning to recognize the need for them and the advantages that they can provide in long-term projects. In summary, methodology and historic data are present, but no clear criteria exist against which appropriate standard acquisitions metadata can be measured.

The research presented in this paper does not demonstrate the level of staff time and cost savings that would be expected over time with the implementation of library automation and that was reported earlier studies on monographs processing. While some failure to incur savings can be traced to the complications of working in an automated environment, user and staff expectations for more and enhanced information in online records, and the challenges of managing electronic resources, the authors believe that the leading cause is the absence of standard serials acquisitions data elements. This absence requires frequent reformatting, reconfiguring, and redesigning data to operate in different integrated library systems and to generate the reports that library managers need.

\section{Method}

The method of Iowa State University's time and cost study largely follows patterns established in the aforementioned ISU-based articles. Readers interested in a more detailed description of this may refer to the authors' previous article. ${ }^{18}$ The methodology is summarized below.

\section{Definitions}

For the purposes of this and earlier studies, cost centers were created to allow analysis of time spent on tasks within ISU's technical services division. Eight cost centers were established by ISU at the outset, which in turn were subdivided initially into 130 and eventually 139 tasks. These centers were then tracked for this study. The centers are divided into two major groups: product and overhead centers. This analysis will look at product center data only. Product centers produce a product or services and include the time included in the following activities:

- Acquisitions: This includes all of the order, receiving, and claiming functions in the department, as well as the maintenance of associated files, but not the selection of materials, which is handled by selectors in the public services and collections division. This section will be discussed in more detail below.

- Cataloging: This includes copy and original cataloging, searching for copy, authority work, recataloging, and internal file maintenance associated with all new title cataloging.

- Volume preparation: This includes all functions associated with marking materials, applying Tattle Tape, and in-house binding.

- Catalog maintenance: This includes all the activities involved in maintaining online databases (public access catalog and serials catalog), card catalogs and shelf lists, making holdings and location changes, and entering into OCLC any cataloging completed off-line.

- Conversion: This covers a long-term retrospective bibliographic conversion project as well as other smaller conversion projects, such as authority and serials Kardex records.

Overhead centers are centers that do not produce products or services, but that support such activities. These centers are apportioned back to the above product centers in order to arrive at the full cost of providing a product or service. These centers include: support services (administrative time, attendance at meetings, non-divisional library and university work, professional service and research, secretarial support, and any other work time not associated with any one center), leave (including vacation, sick leave, and holidays), and automation (the time spent in software development and support, OCLC and some integrated library system support, and the acquisition, utilization and customization of the hardware set-up).

Each center contains common tasks, such as training; procedure and policy documentation; consulting and referring; solving problems; sorting, shelving, distributing, and receiving; and revising. Task definitions were based on logical differentiations between work activities, on identifying activities that were anticipated to change with increased automation, and the uniformity of tasks definitions across cost centers to facilitate analysis on a wider basis. The centers and tasks were originally developed at ISU in the late 1980s. In 1998, a multi-institution study of technical services was initiated with ISU, Vanderbilt University, Cornell University, University of California Santa Barbara, and the University of Missouri-Kansas City. During this three-year study, the centers and tasks were enhanced and validated by successful use by all libraries.

\section{Data Collection}

All technical services staff tracked their work hours during a one-week sample period that occurred initially six times a 
year, but was decreased to four times a year during the third year. This was done in order for the survey to be less arduous on the staff while still retaining statistical significance. The collection periods utilized were selected systematically by the study developers. Time was recorded in quarterhour increments and rounded to the nearest quarter-hour. Individual times were added together to determine the departmental totals for time spent in each task for a given sample week. The time data represented in the accompanying charts represent the total number of hours devoted by all serials acquisitions employees to a given task within a given year, with the annual data being extrapolated from the four to six sample weeks.

In each sample week, the annual salary, including benefits, was gathered for each employee and an hourly salary was calculated. For hourly employees (primarily students), their actual hourly wage was used. Time recorded in each task was multiplied by a given staff member's hourly salary in order to calculate the costs associated with each staff member's task. The cost for each weekly task was the sum of all individual task costs. The data in the graphs represent the annual estimate of costs associated with the task activities of the serials acquisitions staff, again extrapolated from the costs of the weekly sample collection periods.

Each employee was assigned a position number that indicated his or her location in the library organization. If a member held two or more positions in different areas, they were assigned multiple numbers. These numbers were used to sort data by organizational level. The data collected was done so anonymously; any reports issued from the study did not identify individual staff.

\section{The Focus of the Analysis}

This paper focuses on the time and cost data associated with staffing for the serials acquisitions department within the technical services division at ISU. The longevity of the ISU cost center studies has presented a unique opportunity to study consistently gathered data on technical services division costs during a period of great technological and philosophical changes in library operations, both in librarianship as a whole and within ISU's library in particular. During the course of this study, the serials acquisitions department converted from a manual to an online environment and was increasingly required to meet the challenges of maintaining regular work tasks while simultaneously conducting three cancellation projects and two major vendor changes. During this period, the library also started to feel the impact of online publishing and began to phase out print titles while introducing more and more electronic ones. While this first pass through the analysis is historical data, used to validate the sensibility of the methodology, the authors have drawn some conclusions as to future steps-in particular, steps toward true international standards for acquisitions metadata.

The data analyzed in this paper describe the work environment that existed in the serials acquisitions department between 1986/87 and 2000/2001. The authors will examine if the same factors that drove time and costs in monographs also could be applied to the serials environment or if different factors were at work, creating different problems, solutions, and outcomes.

\section{Analysis of the Key Functional Cost Centers}

Analysis of the combined serials acquisitions centers showed a picture that surprised the authors. The amount of time spent in these cost centers had remained fairly steady over all the years of the study (figure 1), unlike monograph acquisitions, which experienced some decreases. Automation had enabled the staff within the department to continue to accomplish their work assignments, expand services by making acquisitions data available to the public and staff, acquire material in the new electronic format, and take over the responsibility for the library's government publications unit, yet the costs of serials acquisitions work steadily increased throughout all of these years (figure 2). While some work processes were streamlined and less-expensive labor was hired to accomplish them, other serials acquisitions work became more complex and required more expensive staffing.

Cost study analysis for the years included in this study shows that the amount of staffing time spent in serials acquisitions tended to stay even over time, but costs consis-

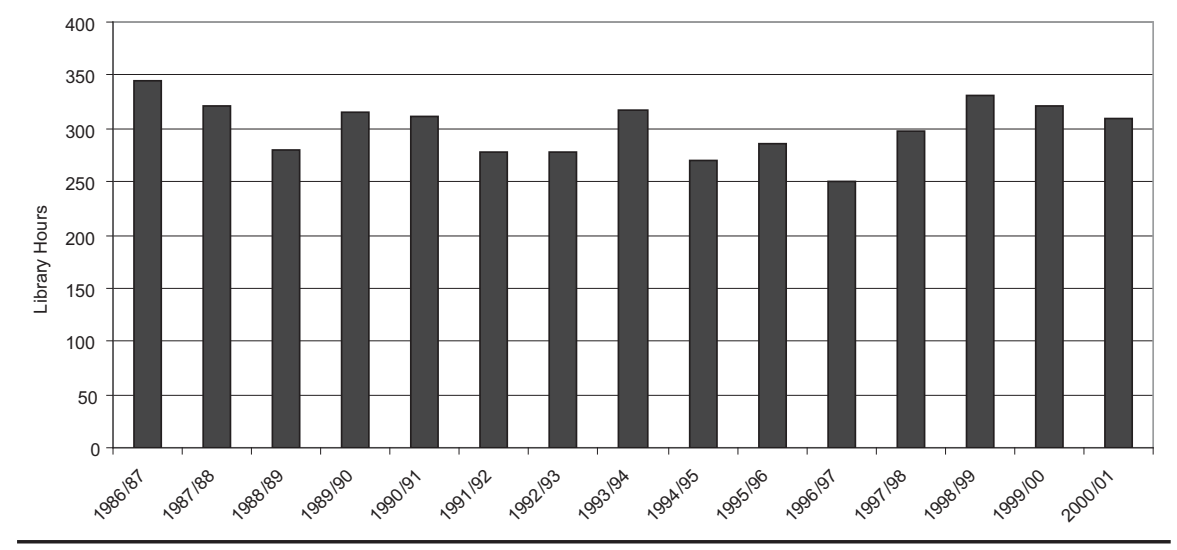

Figure 1 Serials acquisition: time 
tently rose, primarily due to the job reclassifications but also due to general inflation costs.

Figure 3 represents the number of active periodical titles acquired and maintained by the library's serials acquisitions department during the years of the cost study, and may prove useful in providing context for the subsequent detailed analysis. These numbers illustrate the continual trend of a very gradual decrease in the number of active serials until 1996/97, when the processing of government publications was added to the workload of the department. Electronic resource titles were only counted in significant numbers during the final three years of the study, but became a rapidly growing percentage of the total. The numbers of electronic subscriptions for these years were 1,398, 2,177 , and 3,684 , respectively.

The following analysis of the six cost centers for which the serials acquisitions staff members recorded sufficient time to make a detailed examination possible will demonstrate the sensitivity of the data to unique events or projects that affected the department's work. After factoring out these unusual events, the serials acquisitions manager can review the data and determine productive areas in which to change operations with a view toward driving costs down.

\section{Training and Revision}

Training and revision was defined as the category used by individuals training others and also for any staff member being trained and who accomplished no actual work during his or her training session. It also was used for all time spent revising work after it had been accomplished.

Overall time and costs generally rose for this cost center (figures 4 and 5 ), even in the years before automation; however, the greatest increases in time and cost occurred during the automation and conversion years when staff members had to learn new tasks or work processes. Time and costs tended to level off after these spikes had passed. The increases were entirely due to training needs, since automation and increased staff autonomy led to the elimination of revision.

In the early years, many staff positions in serials acquisitions were classified at a lower level (in comparison to later in the study). During these years the department experienced constant turnover and a continual need for training. In addition, departmental restructuring often required long-term employees to undergo training in new or changed work assignments. Training costs during these years were relatively low when compared to the amount of time involved because most of the new staff members undergoing training had less expensive salaries, due to their lower classification.

In 1995/96, time and costs increased significantly (to their highest level), due to the implementation of NOTIS online check-in, which required extensive training for the staff. Subsequent years illustrate how training and revision needs were stabilized after almost all functional processes had been automated through the ILS. Training was required in the newly added responsibility of government documents acquisitions and in the new ILS, but the need for revision was nearly eliminated due to automation. ILS use of bibliographic records as the foundation for all subsequent records removed much of the opportunity for creation of typographical errors. The additional information required to create the acquisitions records only needed to be keyed in once and then could be used to generate subsequent correspondence and purchase orders. Due

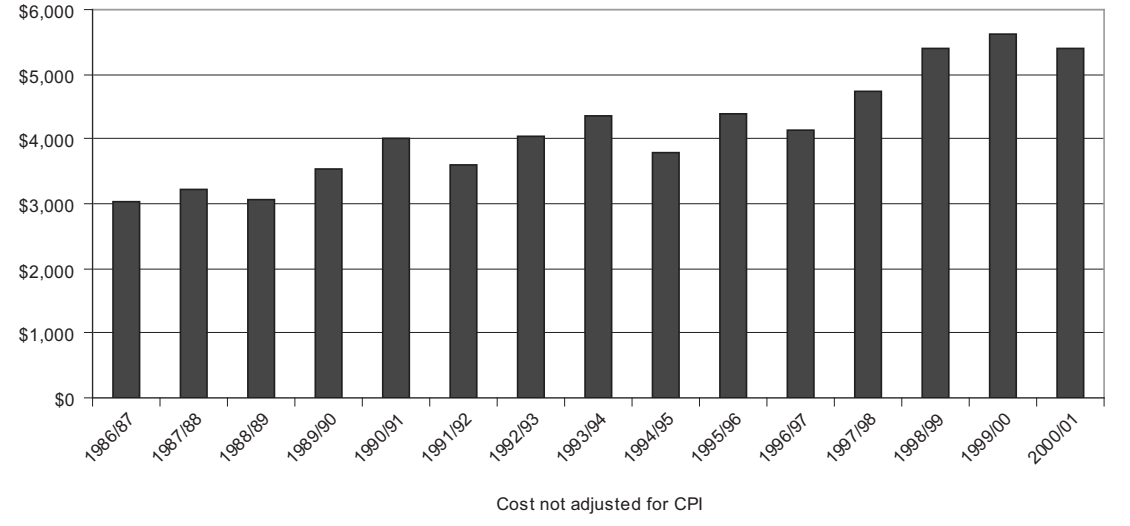

Figure 2. Serials acquisitions: cost

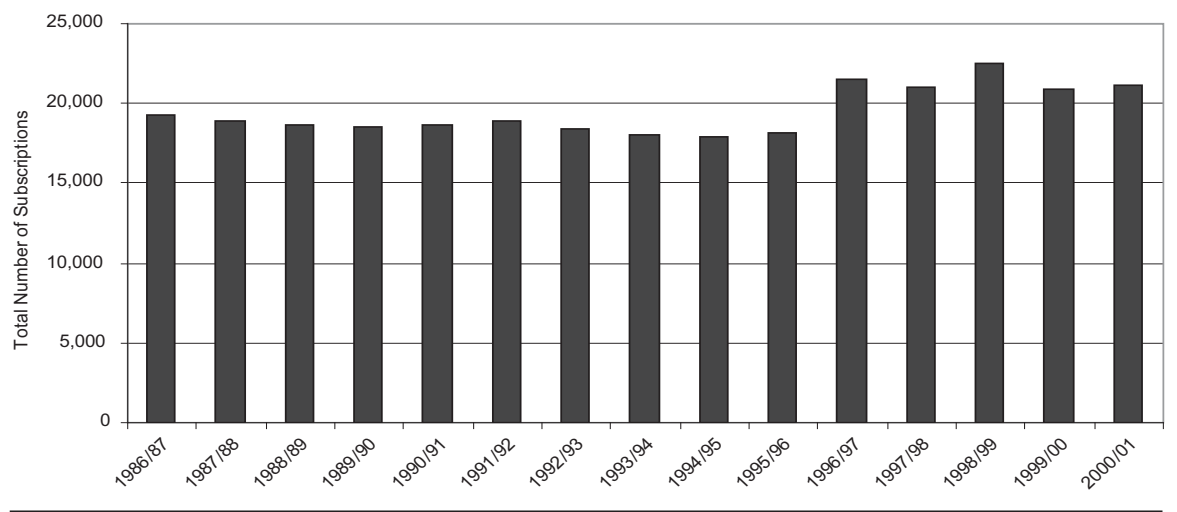

Figure 3. Active serials subscriptions 
to the complexity of the automated system, some of the department's staff members were reclassified and expected to perform self-revision as they completed their work assignments. In 1997/98, the library began relying on student assistants to perform check-in and expected increases in the need for training due to the high turnover in student

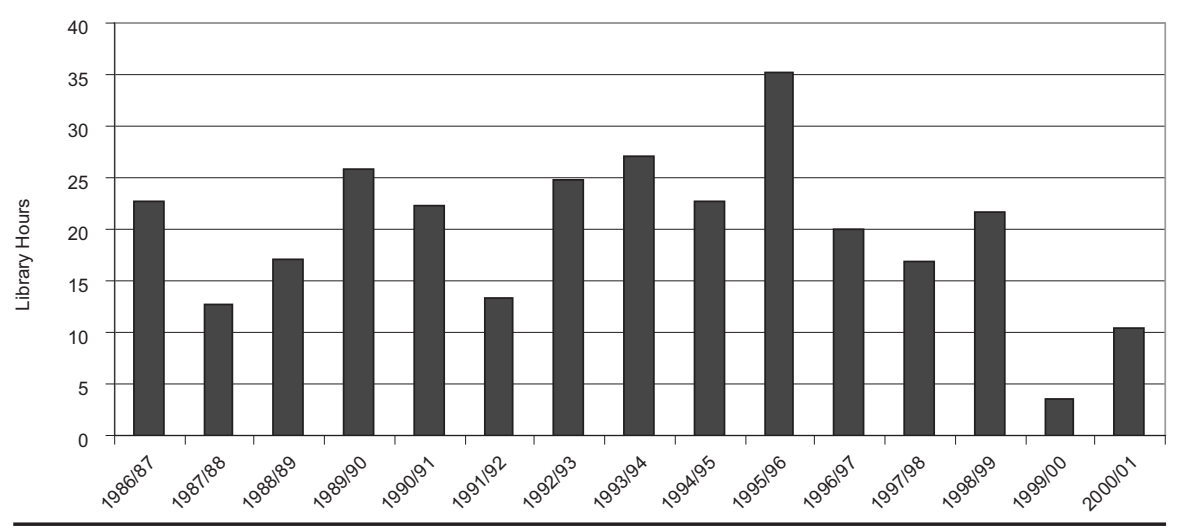

Figure 4. Training and revision: time

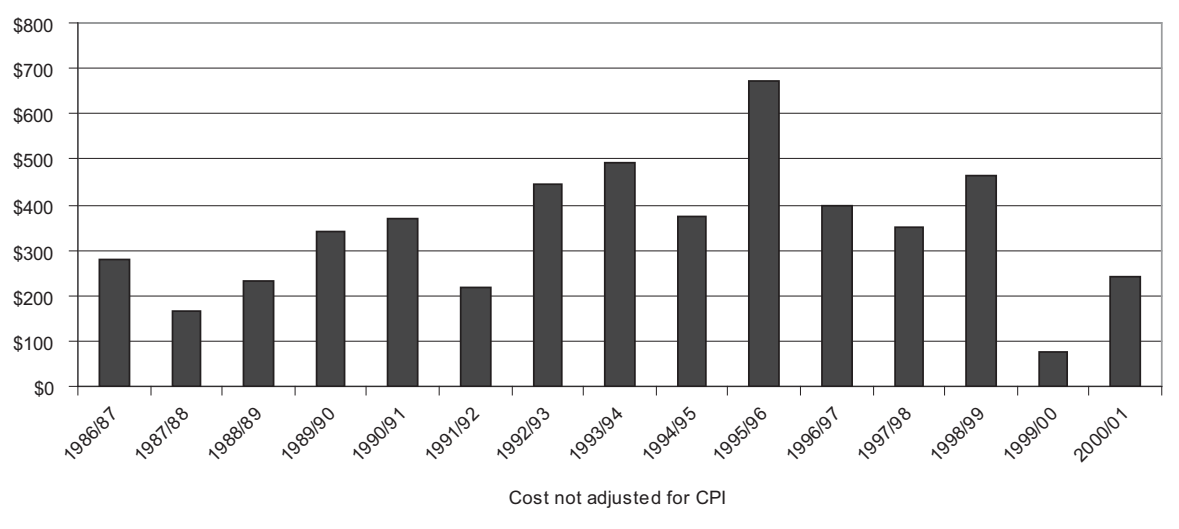

Figure 5. Training and revision: cost

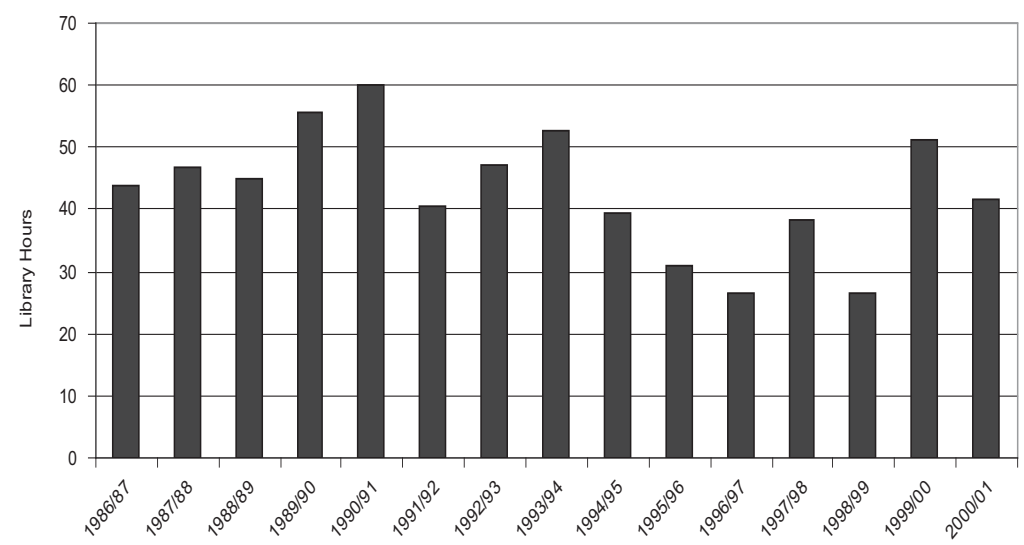

Figure 6. Consulting and problems: time staffing. However, the anticipated training increases did not occur as student workers only required training in routine work, whereas a paraprofessional staff member would have been trained in more advanced problem solving. One anomaly to note is that training was reduced to an all-time low in 1999/2000. This was the year in which staff members had to catch up on activities that had backlogged in the previous year when the new ILS, the Horizon Information Management System, was implemented. Due to the concentration on basic work assignments, no time was available to train staff in new work areas. The following year, 2000/2001, reflected normal training needs occasioned by projects and staff turnover.

\section{Consulting and Problem Solving}

Consulting was defined as the time devoted to conferring with other staff members about acquisitions-related work; problem solving was defined as investigation and research that could not be handled as part of the routine work of regularly assigned tasks.

Time and cost statistics for this cost center display generally increasing activity, which then leveled off until it took a major upswing in the final years of the study (figures 6 and 7). Consultation needs rose in years when major events (cancellation projects, conversion from manual records, system migration, or departmental restructuring) required planning. The years in which these plans were implemented necessarily required less consultation. Reductions in consulting and problem solving reflect the fact that many of the departmental staff were reclassified and given greater autonomy for decision making.

\section{Searching}

Searching time and costs were generally tied to the amount of order- 
ing necessary in any given fiscal year. However, a general level of searching, independent of bibliographer-generated ordering activities, continued because the acquisitions staff members searched local records, bibliographic utilities, published tools, or (in later years) Web sites to obtain information regarding title changes, cessations, frequency changes, delayed publication, and other changes involving journals. The need to continue serials subscription maintenance required this high level of search activity, even in years when the number of serial orders was low.

Figure 8 displays the normally low level of ordering (and thus searching) necessary for the library's subscription operation, because agents continually renewed subscriptions unless a cancellation letter was sent. Major vendor change projects caused the number of serial orders to escalate in two years (1994/95 and 1997/98).

Time and costs from 1990/91 onward show decreases because of efficiencies due to automation of both local and external data sources, ISU's cataloging staff making strides in their retrospective conversion efforts, and access to vendor online databases with reliable and current information. In general, time and cost increases and decreases in searching (figures 9 and 10) tended to follow the ordering history of the department. However, the two anomalous years in which vendor changes drove up the number of serial orders had no impact on time and cost statistics, since the new vendor was able to accomplish much of the ordering and searching activity. One noticeable change in the data, beginning in 1995/96, was that cost levels are appreciably higher than time levels. This was due to the fact that the lower-level staff position that had formerly handled searching had been eliminated, and the higher-paid staff member responsible for ordering now was expected to accomplish both tasks. This was feasible, as fewer print serial orders were placed and searching had been streamlined due to conversion, but this staffing change did affect the expense of searching.

\section{Ordering}

Ordering was the category for all activity associated with placing orders for new subscriptions or for single volumes and backsets. It was also the

Figure 8. Serial orders category for the work of re-ordering subscriptions that had either lapsed with vendors, or that the library had determined should be ordered from another source.

As with searching, the correlation between the number of orders placed and the time and costs required to produce these orders was very strong (figures 11 and 12). The aforementioned anomalies regarding 1994/95 and 1997/98 apply to ordering as well as to searching.

Major work on the 1997/98 vendor change project was done during two weeks, when two EBSCO (the library's serial agent) staff members were physically present at the library to assist in inputting orders and when the library's staff devoted all their efforts to accomplishing these reorders. By happenstance, the cost study survey of staff, which occurred six times a year, did not coincide with either of the weeks of intensive ordering activity.

However, while greater information (which enabled orders to begin with fewer initial start-up problems) was now available to the library staff, the ordering process now required greater experience and judgment to discern relevant data and to choose the best of the many options now

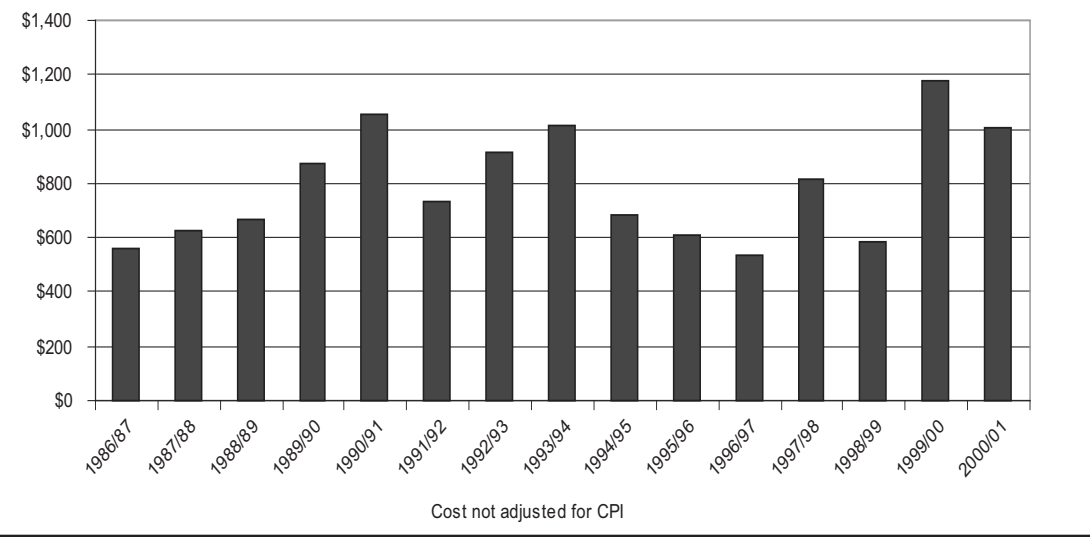

Figure 7. Consulting and problems: cost

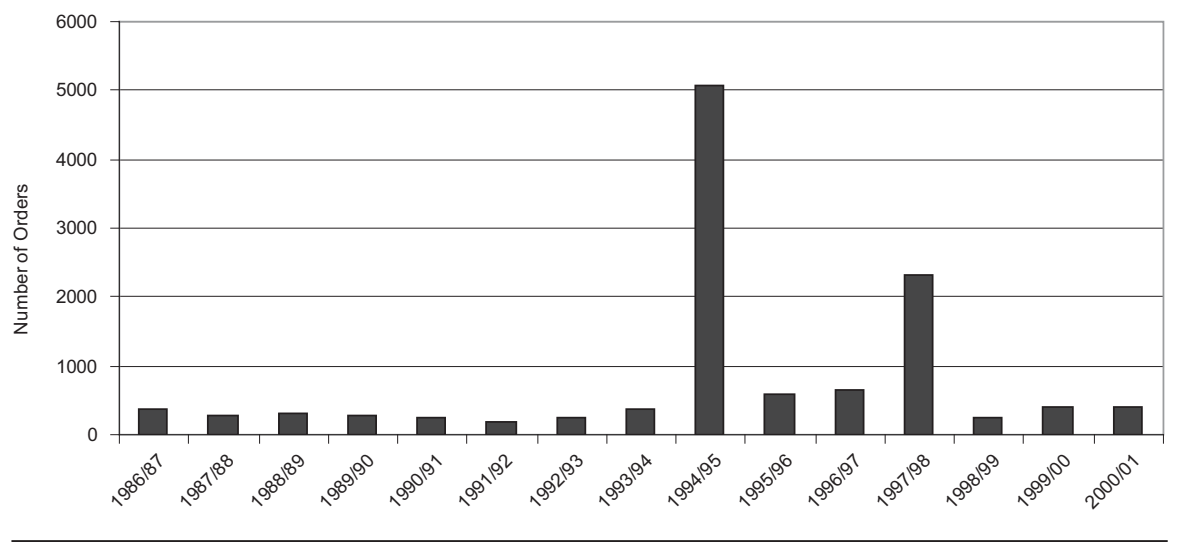


available. It required a high-level staff member to perform it - one who needed to be aware of new trends and who was prepared to set new policy or determine how and when consultation was required. This trend was further exacerbated when ordering of electronic materials increased sufficiently to require hiring an electronic resources coordinator. A professional librarian was hired for this job because ordering online material often required complex, time-consuming negotiations and knowledge of legal documents, such as licenses. A fruitful area for future analysis by the library will be determining how to lower ordering costs by finding new ways to streamline the process and sufficiently standardize procedures so that it can be delegated to the lowerlevel staff.

\section{Record Maintenance}

The types of work assignments that were called "record maintenance" were defined fairly broadly. This category was used to count any time a record needed to be updated in some way. It encompassed claiming, annotating serial records regarding delayed publications, and numbering notes or frequency changes as well as processing title changes, cessations, and cancellations. It also was the category to which staff assigned their time when they worked on record clean-up projects. A comparison of the time and costs associated with this task through the years indicates that it was a time-consuming but relatively low-cost activity center in earlier years (figures 13 and 14). The amount of time then fell significantly but the costs remained at their former level, indicating that the greater efficiencies in the work activities were more than balanced by the need for higher-level staff to accomplish them. Time and costs became closely aligned in this task; both climbed to a new plateau during the last years of this cost study, when the library migrated to its new ILS. Record maintenance is the cost center that most clearly illustrates the problems that result from a lack of standardized acquisitions data elements. Many of the record clean-up projects would not have been necessary had the library been able to draw upon a national body of experience before creating its acquisitions records. In particular, projects addressing the linkage of Horizon records could have been avoided if the library had had the benefit of learning from other experienced ILS customers and had been able to script linkage creation into the migration development.

The amount of time spent in record maintenance was quite high in the earlier years compared to later, but the

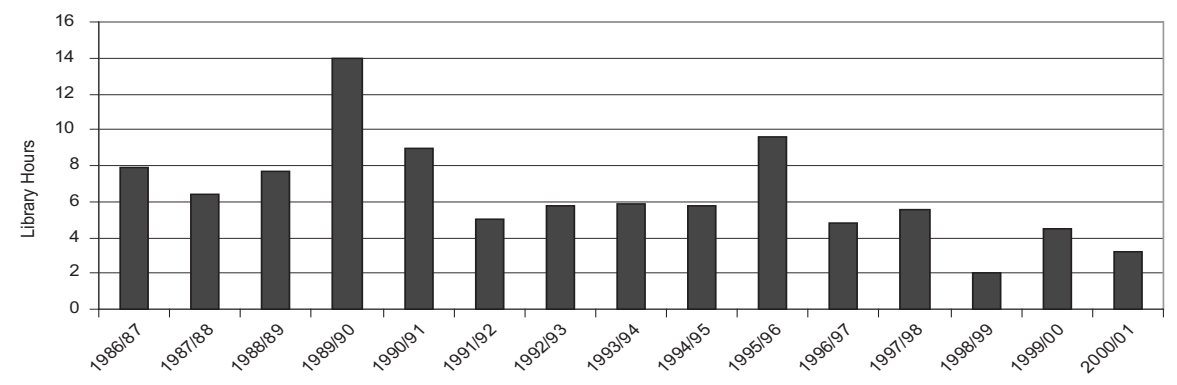

Figure 9. Searching: time

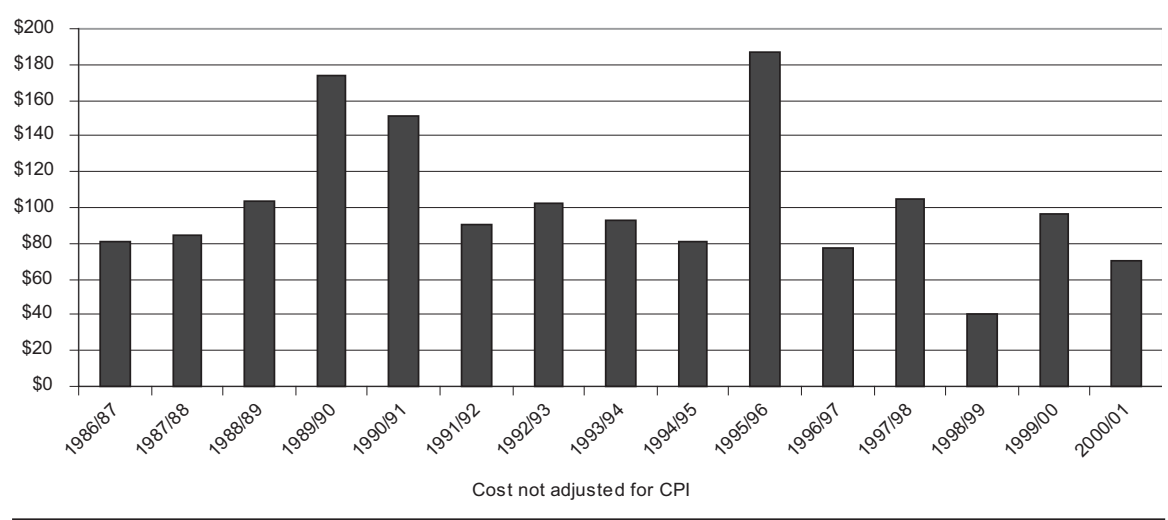

Figure 10. Searching: cost

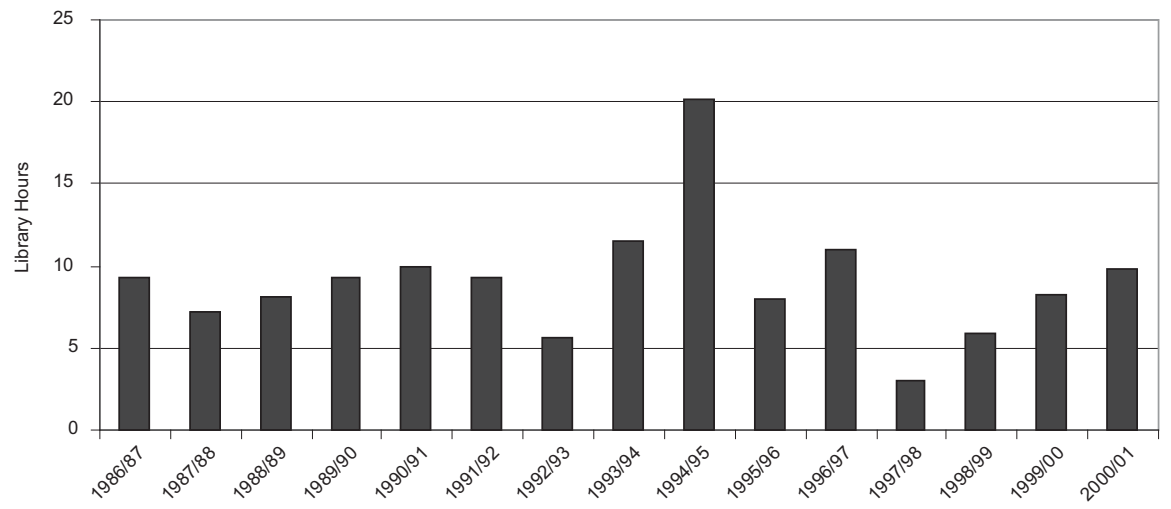

Figure 11. Ordering: time 
costs were low, illustrating the impact of the library's first major cancellation project. During these years, the gathering of information as preparation for cancellation decisions was a manual process due to the lack of automation and was assigned to the department's lowest classified staff and to students. These staff members had to compile a massive list of current price information, taken from prices written on Kardex cards, in order to aid the bibliographers and campus faculty in their cancellation choices.

Starting in 1988/89, time and costs remained remarkably level for ten years, despite another cancellation project accomplished during the manual Kardex era, major vendor changes involving thousands of subscriptions, and the automation of serials Kardex activities. The cancellation project relied heavily upon data that had been collected during an earlier cancellation review and so was processed without too much additional research; the vendor change project was accomplished with the assistance of the new vendor.

During the final years of the cost study, record maintenance data reflect the migration to Horizon and the nearly constant clean-up projects required. These projects were initially required due to the implementation itself and later because of the need for better reports and statistics. As a result of these continuing tasks, time and costs rose precipitously and remained high. The change to the new ILS and the raised expectations regarding the many flexible reports the system could be capable of producing meant that record maintenance became a higher profile activity. These projects were time-consuming, and many were performed under a tight timeframe because of deadlines expected for report generation. The greater flexibility of the Horizon system led to administrators and staff envisioning new types of data to be generated or ways to convert manually maintained statistics into more accurate machinegenerated statistics. Most of these needs became apparent only after the

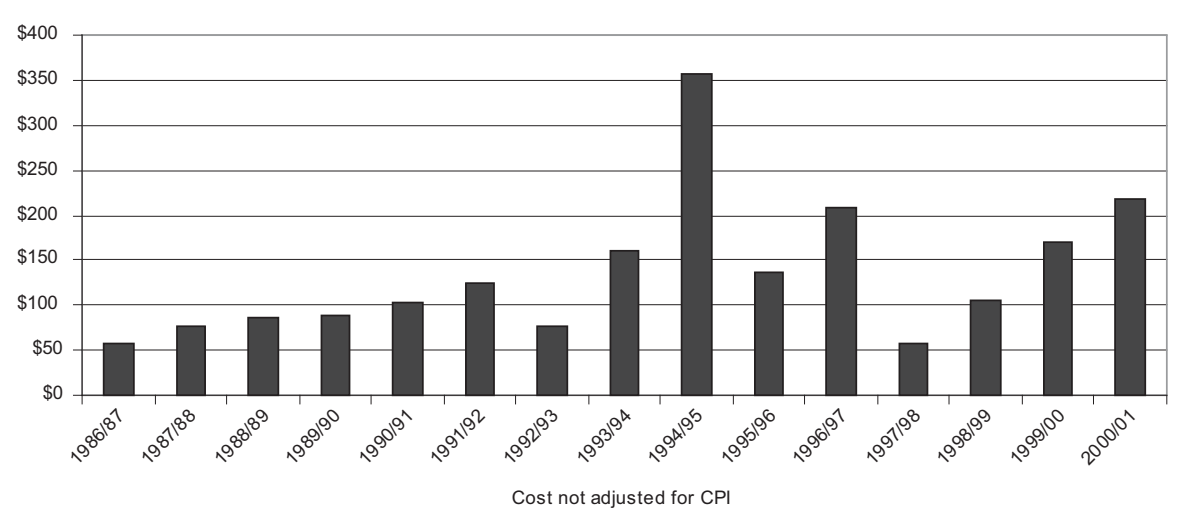

Figure 12. Ordering: cost

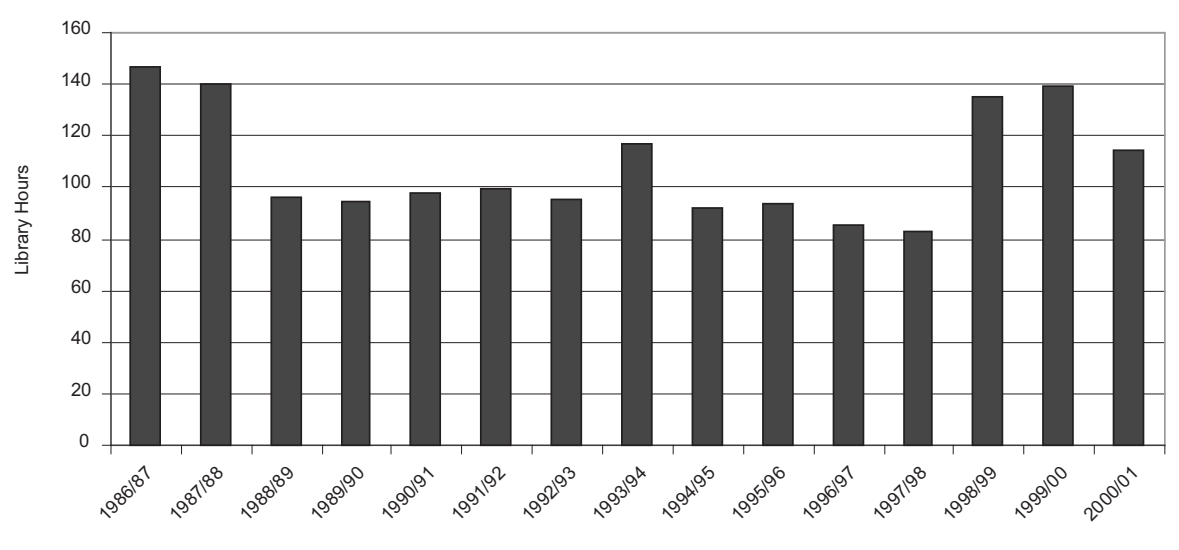

Figure 13. Record maintenance: time

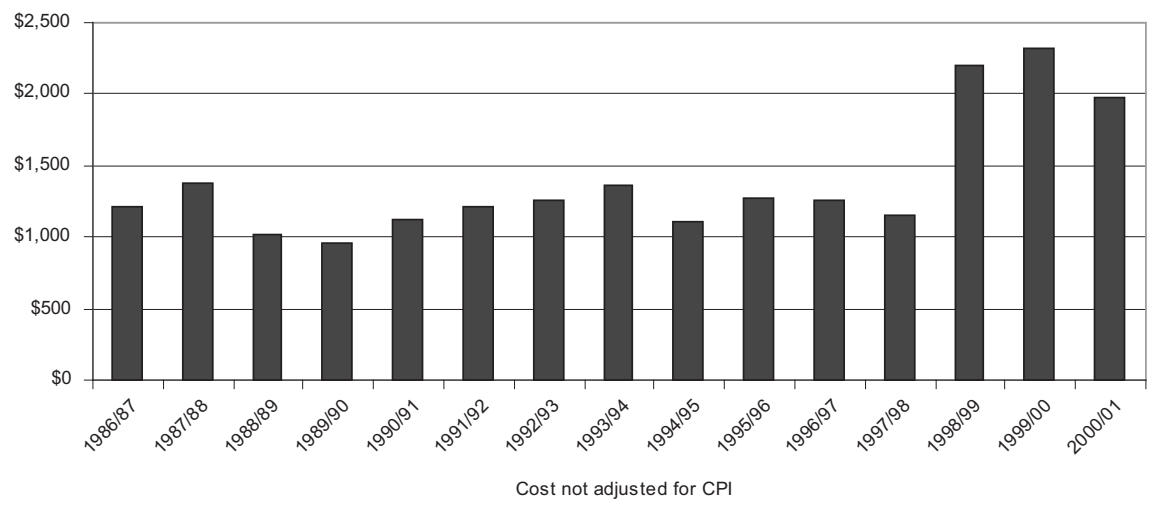

Figure 14. Record maintenance: cost 
migration, a third cancellation project, and modifying the claims process to expand acquisitions of out-of-print issues. As previously mentioned, the department filled a new faculty position in 1998/99, that of electronic resources coordinator for acquisitions. In addition to ordering electronic materials, this position was also responsible for registering for access to free online materials or online resources to which the library had rights because of print subscriptions. This registration work was recorded in the record maintenance category.

\section{Receiving}

Receiving was the cost center category for the work associated with receiving serials material: check-in, labeling, and marking. It also included the opening and sorting of mail. Costs tended to increase within this activity center, even in years when time was decreasing (figures 15 and 16). Online check-in gave the library benefits in terms of public access to receipt information and better access to receipt records for the library staff, but it did result in a more complex and time-consuming work process, requiring the reclassification of the staff. Efforts were made to streamline the workflow in order to make it suitable for less expensive staff (students) to accomplish.

During the earliest years, time within this cost center remained stable, but costs slowly rose. Beginning in 1991/92, time spent in receipt tasks began to decrease; costs did not. The number of receipts (figure 17) also began to decrease during this period, as a direct result of cancellation projects.

Automation of check-in operations had the result of increasing the amount of time spent in receipts, starting in 1995/96; costs also rose, but at a greater rate. Staff, who formerly had been able to place a checkmark on a Kardex card, now had to create a receipt statement on the NOTIS Order/Pay/Receipt (OPR) record and

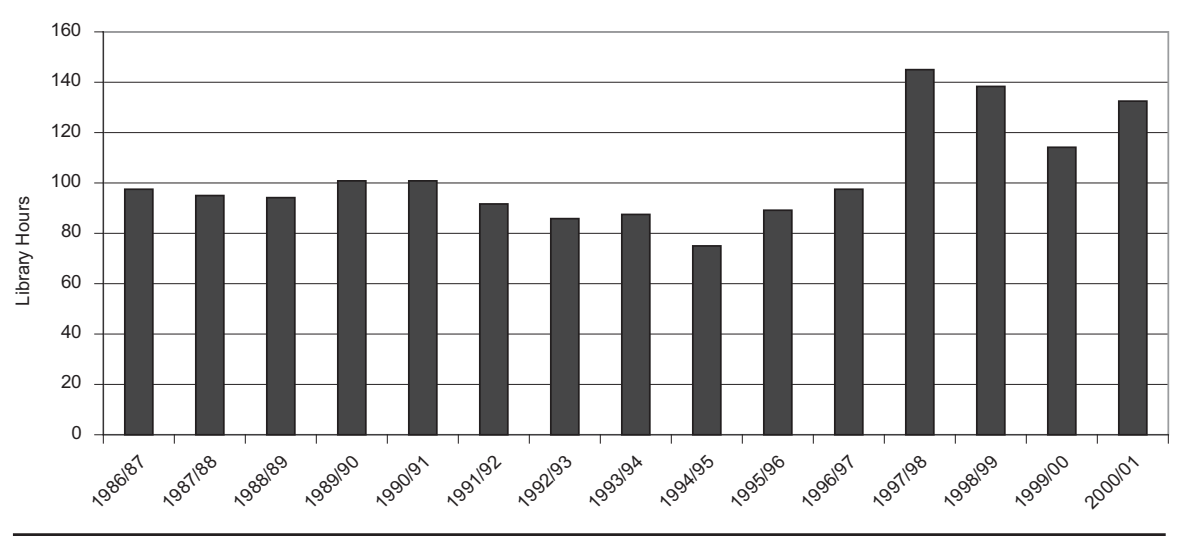

Figure 15. Receiving: time

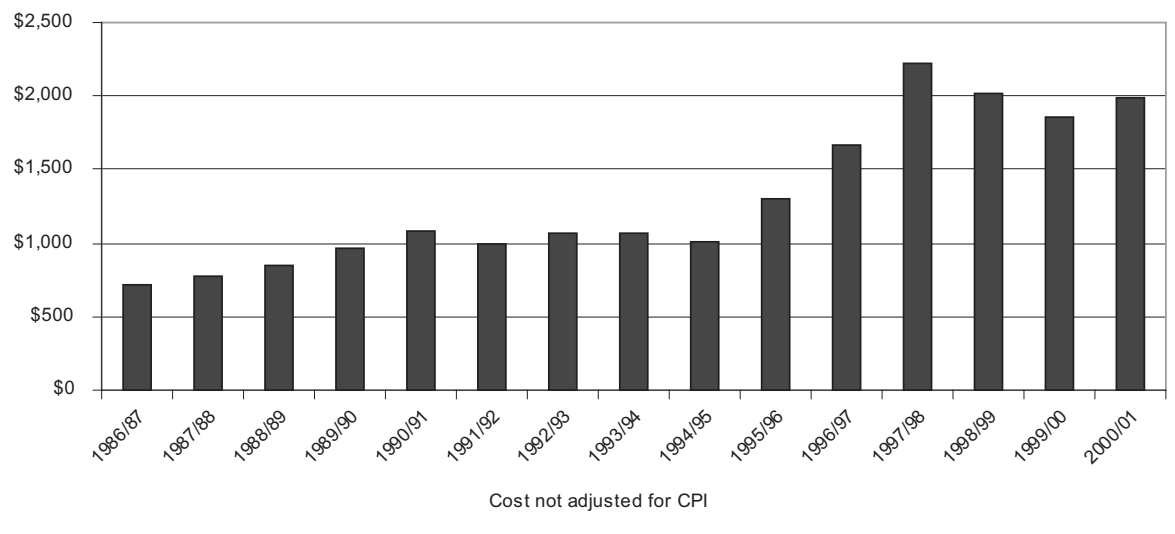

Figure 16. Receiving: cost

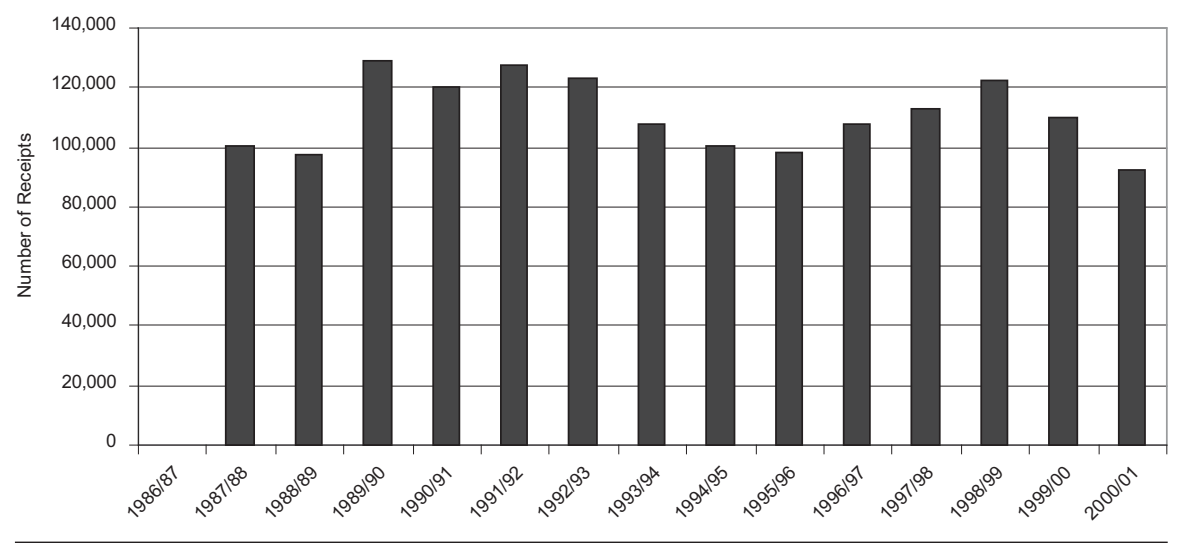

Figure 17. Serials acquisitions receipts 
system's predictive check-in module. Some side benefits occurred for the acquisitions staff, as online check-in data reduced the number of enquiries from both the public and non-acquisitions staff and enabled staff members to have constant access to the check-in records. In the following year, 1996/97, time, costs, and the number of receipts all increased. These data reflect an increased amount of time required for the automated process, but the increase in numbers illustrates that staff were able to clear the backlogs that initial implementation had developed.

In 1997/98, time and costs rose to an all-time high. This was primarily due to the integration of the former government documents unit into serials acquisitions, which added both staffing and work to be accomplished. The number of receipts also rose this year, with the receipt of United States depository documents accounting for most of the increase.

During the final three years of the study, decreases in time and costs for receipts reflect the decline in the number of paper-based receipts after the library canceled print journals in order to acquire online subscriptions. Receipt data also reflect an increase in the amount of depository publications produced in electronic formats. In addition, the costs for receipt activity decreased at a greater rate than did time, illustrating the benefits of a managerial decision to employ less costly student employees to perform routine check-in duties. The library anticipates continuing to reduce time and costs for receipts as more receipt-based activities are standardized procedurally and as the trend to migrate from paper serials to electronic subscriptions accelerates.

\section{Additional Factors Affecting Serials Acquisition Analysis}

The biggest distinction that defines serials acquisitions, as opposed to library acquisitions in general, is the longterm investment that libraries have made in their serials subscriptions. Maintaining acquisitions data for serials and monographs is crucial for daily work functions and is essential for informed collection development management. Such maintenance is usually mandated by auditing authorities. However, in the case of serials, the pressurefilled economic and publishing environment has made historic acquisition analysis of specific serial titles even more important. Thus, the lack of well-defined standards hits this field of acquisitions even more drastically than it does monographs acquisitions. Serial subscriptions are subject to annual price increases, with some disciplines tending to increase at more astronomical rates than others, making collection management decisions regarding these resources an ongoing responsibility. Subscriptions are further subject to a variety of possible financial arrangements in packages or combination subscriptions, which also are likely to change on a yearly basis. Subscriptions are typically prepaid, which is not the norm for monographs, and receipt of individual serial issues is less certain and also may suffer from unsuccessful claiming. Due to the high profile these subscriptions have on university campuses, consideration of how to maintain strong and flexible management data regarding these subscriptions is essential.

\section{General Advances in Technology}

Advances in automation, such as the advent of personal computers and e-mail, have lessened the need for clerical work. Letters and reports can be prepared by a document's originator rather than being drafted and handed to the departmental secretary to finish. Personal computers have enabled the staff to create claim letters based on established templates. These letters appear to be individually typed and thus elicit a better response from the publisher than the library's old claim form. In later years, staff also began using e-mail messages for claims or utilizing the online claim system set up by subscription agents. When the integrated library system's ability to produce claims and purchase orders became a reality after the NOTIS conversion, this also sped up the production of correspondence and made it more accurate, since the ILS supplied the vendor name and address, title, and other bibliographic data, as well as acquisitions data, such as the purchase order number.

Cancellation projects were greatly expedited by automation and word-processing. Although the 1999/2000 cancellation process was still time-consuming for the serials acquisitions staff, the advance preparation work accomplished in creating relevant data fields in the library ILS for use in producing accurate lists and the ability to prepare and generate cancellation letters through word processing and spreadsheets streamlined the process considerably. During the two earlier projects, bibliographers had been required to send their cancellation requests to the department by February in order to write all of the cancellation letters and update records in time. In the 1999/2000 project, the acquisitions department was able to give the bibliographers until June to forward their requests to the department and was still able to accomplish the cancellations by the end of the fall renewal period.

\section{Staffing Changes}

The conversion to NOTIS and the added complexity of the receipt work caused the library to reclassify the lower-level staff positions. Some changes in the classifications of some upperlevel staff occurred when restructuring and administrative changes resulted in the elimination of a vacant faculty position. However, in later years another faculty position was created when the need for staffing devoted to electronic resource pro- 
curement became apparent. In 1997/98, serials acquisitions was able to separate the routine from the complex check-in duties and to hire students to perform routine check-in when a lower-level staff position responsible for check-in became vacant. This change helped contain the increasing cost of serials acquisitions activities and to keep the costs from rising higher than they otherwise would have.

\section{Restructuring}

Serials acquisitions was involved in a large number of restructuring initiatives over the years of the cost study. One important change that affected the department's time and cost study centers was the addition of the government publications unit to serials acquisitions in July 1997. It was integrated with all of its workload duties, but required fewer staff than it had when independent. It had been previously administered by a high-level staff member, but this position did not transfer along with the other staff and work. Instead, the department received additional funding to hire student assistants. Serials acquisitions personnel had only recently automated their own work and were able to recognize ways in which specialized government documents workflows could be streamlined yet still remain suitable for government depository requirements

\section{Electronic Serials}

Over the years of this cost study, electronic serial resources have evolved from a few indexes and abstracts in a CD-ROM format to a vast number of complex resources that have changed the nature of acquisitions work and subsequently redefined staffing needs. By 1999, the ISU library had realized the need for a full-time staff member to handle the acquisition of these resources-a professional librarian with the broad perspective to understand how this work would need to change over time in an evolving area of publication and librarianship. This staff member needed to be able to undertake difficult and frustrating publisher communications and to deal tactfully with both library staff and patrons in handling expectations that this material could be obtained instantly.

Acquisition of electronic resources is characterized by complex subscriptions arrangements, which can include partnerships with other libraries, packages involving multiple titles, and license clauses prohibiting cancellations of either print or online titles within the time period of the signed license. The yearly renewal period of serial subscriptions has developed into a time of frantic consultation with other library colleagues and vendor representatives, all under very tight timeframes. The more recent trend of obtaining a large number of online journals in publisher packages has brought to the fore a new problem: what would happen when a publisher bought a new journal or, worse, sold off an old journal? The library could lose access to the new issues of the journal in question, unless it subscribed to the journal separately or it became part of another publisher package that the library already had.

This had never been a problem in the print environment, where the library's serials agent ordered titles without the need for any action on the library's part. As the library continues the trend to migrate from paper to online serials, acquisitions management needs to assess the impact on staffing. ISU can anticipate that less staffing will be needed for check-in of paper issues, but the amount of work involved in acquisition, claiming, maintenance, and record keeping of electronic resources has grown beyond what one person can handle.

\section{Local Serials Acquisitions Code Creation}

ISU library managers first recognized the need to create local standards for acquisitions data elements during the preparation for automation of manual records in the NOTIS system. Analyzing the library's likely future needs led to the identification of key pieces of data that were required for inclusion in unique fields where they could be manipulated for reporting purposes. The subsequent use of these data elements for reports and statistics proved their worth, so that they were retained for the ILS migration to Horizon. In addition, the greater flexibility found in Horizon's relational database led to the creation of more fields for data elements and further refinements of the existing codes. In some of the clean-up projects associated with the record maintenance cost center, staff had to retroactively key information within existing records in order to enable the library to use the new or redefined data fields.

The following proved to be the most significant data elements:

- Estimated annual cost. This field was particularly valuable for allocating cost when serial titles came in combination packages. It was updated whenever invoices were paid. In conjunction with the subject code (see below), this field enabled the library to manage subscriptions and standing orders and to prepare for required cancellation projects by producing cost comparisons in the various subject disciplines over the course of the years. These locally generated statistics were considered to be more valid by the campus community than any vendor-produced report had been, because the vendor reports only covered portions of the library's serial subscriptions.

- Subject code. For management purposes, the subject code could not be linked directly to the fund code, since the library required the flexibility of altering this code as academic disciplines changed, or as jour- 
nal content changed.

- Claiming code. This was used to sort claims so that subscriptions, gifts, and exchanges could be reviewed by the appropriate individual within the department and to enable the library to prioritize claims. An unanticipated side benefit to this field was its usefulness in identifying electronic materials for library surveys and expenditure reports.

- Subscription publisher code. This code was particularly meaningful in tracking the expenditures involving publishers that produced expensive titles. It has proved its usefulness time and again when the library has been asked to participate in Association of Research Libraries (ARL) surveys or questionnaires. Bibliographic fields for publisher information in the MARC records had been deemed inadequate for serial subscription management information, as the publisher field was based on a single issue (usually the first one), and the library could not depend upon the bibliographic record containing current publisher information.

- Combination purchase. This field identified titles with financial relationships to other titles. It was used in cancellation project preparation, since it highlighted the subscriptions where complex decision making were required and was used to alert library staff that the estimated annual cost of more than one title might be affected by an invoice.

- Linkage. These fields were already in existence in Horizon. The library's information technology staff made them visible and alterable, which was essential given the relational database structure of Horizon and the way in which the library envisioned utilizing acquisitions data elements located in various modules.

The need for more standardized fields of acquisitions data elements has become very apparent. Planning for the local fields necessary for building and maintaining an electronic subscription and license database is currently underway at ISU and would have benefited significantly from extractible data fields that had been uniformly constructed according to universal acquisitions data elements. Extrapolating from personal knowledge about how useful the local codification of acquisitions data elements has been at ISU, the authors speculate that the pooled experience of other professional acquisitions managers would reveal unforeseen possibilities.

\section{Conclusions}

Serials holdings have evolved to become one of the most important indicators of a library's value as a resource for disseminated scholarship and information. ARL includes current serial totals in the list of eighteen benchmarks used in ranking ARL members. ${ }^{19}$

This analysis of ISU's serials acquisitions activities demonstrates the difficulty in trying to control or reduce the time and costs associated with acquiring these resources in an environment where automation speeds up routine functions and improves accuracy, but also raises user expectations and requires considerable staff empowerment for decision making. The most fruitful area for serials cost containment has proven to be record maintenance, wherein a great deal of post-automation time and resources have been placed.

One of the most compelling needs shown is the requirement to have standards applied down to the most granular level possible of the serial acquisition record. Automation in serials acquisitions can accomplish much. However, the need to constantly rethink and reconfigure data, usually manually, in response to new demands for information, call for the need for more thorough and rigorous restructuring of acquisitions records. This is compounded by the long usage life of serials records as compared to monograph records, which only need to be worked upon for the duration of a single ordering event. At ISU, the discrete local fields created in NOTIS were easily migrated to the new ILS, Horizon, and continue to function usefully in providing flexible data and enabling greater efficiency of acquisitions workflows.

The ISU library has often required the acquisitions department to produce various reports for management tools or surveys, which has either necessitated that the department undertake a major project to make the online records more suited to new library needs (such as creating or correcting links to bibliographic records and copy records) or the creation of new local fields. This has required acquisitions staff to spend a considerable number of hours completing various individual requests, a number that could be significantly reduced or eliminated by introducing uniform data elements into serials records. Such standard elements would enable the extraction of more useful data fields for such reports than is now currently possible, without those standards being in place. If the acquisitions department had not needed to pursue these activities, possibilities for reducing staffing, accomplishing new initiatives, and providing the library and its patrons with improved service would have existed.

Individual libraries are now committing time and money to create separate sets of standard data elements, a continual reinvention of the wheel. As a library's ILS undergoes upgrades, the library is then required to expend further time and effort to ensure that the local modifications migrate to each upgrade, which in some instances may be impossible. If these local modifications were used to inform 
the creation of unified national or international standards of mandatory and optional acquisitions fields, all would benefit. Local standards are not really standards at all. An industrywide and academiawide set of standards for acquisitions processing information, defining how acquisitions librarians can parse, encrypt, display, and utilize this information, would enable many libraries to reap huge benefits in terms of management data, and of finding opportunities for reassigning staff time to meet new needs.

\section{References}

1. Karen Calhoun, "Technology, Productivity and Change in Library Technical Services," Library Collections, Acquisitions, and Technical Services 27, no. 3 (Autumn 2003): 283.

2. Dilys E. Morris, "Staff Time and Costs for Cataloging," Library Resources \& Technical Services 36, no. 1 (Jan. 1992): 79-92.

3. Ibid.; Dilys E. Morris and Lori Osmus, "Serials Cataloging Time and Costs: Results of an Ongoing Study at Iowa State University," The Serials Librarian 22, no. 1/2 (1992): 235-48; Dilys E. Morris and Gregory Wool, "Cataloging: Librarianship's Best Bargain,” Library Journal 124, no. 11 (June 15, 1999): 44-46; Dilys E. Morris et al., "Cataloging Staff Costs Revisited," Library Resources \& Technical Services 44, no. 2 (Apr. 2000): 70-83.

4. Pam Zager Rebarcak and Dilys E. Morris, "The Economics of Monographs Acquisitions: A Time/Cost Study Conducted at Iowa State University," Library Acquisitions: Practice d Theory 20, no. 1 (Spring 1996): 650-76.

5. Dilys E. Morris, Pamela Rebarcak, and Gordon Rowley, "Monographs Acquisitions: Staffing Costs and the Impact of Automation," Library Resources \& Technical Services 40, no. 4 (Oct. 1996): 301-18.

6. David C. Fowler and Janet Arcand, "Monographs Acquisitions Time and Cost Studies: The Next Generation," Library Resources \& Technical Services 47, no. 3 (July 2003):
109-24.

7. Sandra K. Paul, "The Future of Standards," Library Acquisitions Practice o Theory 12, no. 2 (1988): 235-38.

8. Sally W. Somers, "Standards! Standards! Standards! Experiences with Standards at the University of Georgia Libraries," Library Acquisitions: Practice \& Theory 11, no. 4 (1987): 367-72.

9. Katharine Treptow Farrell and Marc Truitt, "The Case for Acquisitions Standards in the Integrated Library System," Library Collections, Acquisitions \& Technical Services 27, no. 4 (Winter 2003): 483-92.

10. Ibid., 487.

11. Ibid.

12. Ibid., 488.

13. Nancy Slight-Gibney and Mary Grenci, "Starting with an Empty Map: Benchmarking Time and Costs for Serials Operations," The Serials Librarian 46, no. 3/4 (2004): 287-93.

14. Roger C. Schonfield et al., The Nonsubscription Side of Periodicals: Changes in Library Operations and Costs Between Print and Electronic Formats, CLIR Report No. 127 (Washington, D.C.: Council on Library and Information Resources, 2004). Accessed Sept. 10, 2004, www.clir.org/pubs/reports/ pub127/pub127.pdf.

15. Ibid., 36.

16. Association for Library Collections \& Technical Services Automated Acquisitions/In-Process Control Systems Discussion Group. Accessed Sept. 10, 2004, http://archive.ala. org/alcts/div/automation.html.

17. Association for Library Collections \& Technical Services Automated Acquisitions/In-Process Control Systems Discussion Group, "Archives of AUTOACQ-L@LISTSERV. ND.EDU: Acquisitions Automation Issues.” Accessed Sept. 10, 2004, www.lsoft.com/scripts/wl.exe?SL1=AUTOACQL\&H=LISTSERV.ND.EDU.

18. Fowler and Arcand, "Monographs Acquisitions Time and Cost Studies."

19. Association of Research Libraries, ARL Statistics 200102 (Washington, D.C.: Association for Research Libraries, 